\title{
Research on the Relationship of E-Commerce Livestreaming and Sales Performance of Manufacturers —An Empirical Study of Tmall Transaction Information System
}

\author{
Zhenghua Deng ${ }^{1}$, Xiao $\mathrm{Hu}^{2}$ \\ ${ }^{I}$ School of Economics and Business Administration, Chongqing University, Chongqing, China \\ ${ }^{2}$ School of Economics and Management, Chongqing University of Posts and Telecommunications, \\ Chongqing, China
}

\begin{abstract}
With the rapid development of industry, the e-commerce livestreaming, which is becoming popular in recent years, poses many interesting challenges and opportunities for manufacturers. To explore the influence mechanism of e-commerce livestreaming on sales performance, this paper studied the impact of e-commerce livestreaming from both sales volume and consumer satisfaction, and studied the combined effect of e-commerce livestreaming and third-party recommendation on sales performance. The results show that e-commerce livestreaming has significantly boosted the sales of goods. Consumers with low purchasing power are more susceptible to e-commerce livestreaming than those with high purchasing power. Further tests show that third-party recommendations had the positive action on the influence relationship between e-commerce livestreaming and the purchases of consumers with low purchasing power, as well as on e-commerce livestreaming and the satisfaction of consumers with high purchasing power.The conclusion provides theoretical basis for enterprises to use big data of transaction information system to improve marketing efficiency.
\end{abstract}

Keywords:manufacturers, E-commerce livestreaming,sales performance, consumer satisfaction

\section{Introduction}

With the rapid development of e-commerce in China, online consumption has shown an exponential growth. According to CNNIC statistics, in 2017, the number of online shoppers in China reached 533 million, and the utilization rate reached $69.1 \%$, an increase of $14.3 \%$ compared with 2016 . The online retail sales amounted to 7.18 trillion yuan, of which the retail sales of physical goods were 5.48 trillion-yuan, accounting for $15 \%$ of the total retail sales of consumer goods (The data comes from the 41st Statistical Report on China's Internet Development Status released by China Internet Network Information Center). Online shopping has become an important part of modern business activities, and people's consumption behavior is deeply affected by network and network information. In recent years, especially since 2015 , online live has rapidly developed into a new Internet format. By the end of 2017, the number of users of online live in China has reached 325 million, accounting for $45.8 \%$ of the total number of netizens. Many brands have adopted live video streaming as a new way of selling commodities.

At present, almost all e-commerce websites in China have opened live platforms. taobao.com has nearly 5,000 daily live broadcasts, and the number of users watching Taobao live broadcasts reaches 10 million. Compared with the traditional online commodity description by pictures and texts, e-commerce livestreaming is more accurate and interactive to target groups, and more effective in conveying brand connotation and directly affecting consumers' emotions. In April 2016, Maybelline invited Angelababy to launch new commodities on the Taobao live platform. The two-hour live broadcast was watched by more than 5 million people, and 10,607 lipsticks were sold, with sales of RMB1.42 million. E-commerce livestreaming is characterized by buying while watching. In the process of shopping, consumers can communicate directly with the sellers more conveniently, see the on-site trial of the commodity in the live video, and more realistically grasp the function and appearance of the commodity no longer limited by the beautified pictures, which improves the user experience. It builds a highly participatory shopping scenario for consumers. On the one hand, the anchor can constantly change the presentation according to the user's ISSN: 0010-8189 
speech in the live, and consumers are allowed to get more information of their own attention. On the other hand, it helps participants identify the interactions of potential customers, new customers and old customers through setting the level of fans participating in the live selling by brand sellers, which provide reliable purchasing reference and reduce the perceived risk caused by information asymmetry and network information anonymity.

Although, e-commerce livestreaming has brought high click-through rates to many brand sellers, it does not necessarily lead to high sales. There are significant differences in the performance of e-commerce livestreaming of various brands. Most of the existing research literature on network live broadcasting focuses on its development status, governance and supervision [1,2] and its dissemination effect [3], while less attention is paid to e-commerce livestreaming. The essence of e-commerce livestreaming is a special form of online selling, which is different from traditional online selling in terms of live publisher, commodity displays, and interactive relationships. Do these differences affect purchasing behavior and feelings of consumers? As the current research on network live broadcasting cannot cover all characters of e-commerce livestreaming, and there is a lack of research on the specific impact mechanism and economic consequences of e-commerce livestreaming. Then, it is of great theoretical and practical significance to study the influence mechanism of e-commerce livestreaming on purchasing behavior and feelings of consumers.

In May 2016 the official launch of the Taobao live broadcast platform which was positioned as a consumer live broadcast provides us with a research opportunity. In this paper, we take the beauty commodities with more online sales as the research object to study the relationship between e-commerce livestreaming and sales performance. The research has the following contributions:(1) it discussed the relationship between e-commerce livestreaming and sales performance, which is helpful to reveal and understand the influence mechanism of e-commerce livestreaming on consumers' purchase decisions and post-purchase feelings, and expand the research related to e-commerce marketing.(2) Considering the purchasing power constraints of consumers, this paper differentiated the impact of live broadcast sales on the decision making and psychology of different types of consumers, and improves the reliability of the research.(3) The research conclusion is of strong practical significance. In recent years, e-commerce livestreaming has become a popular marketing tool used by e-commerce companies. This research can provide some empirical evidence for the selection of e-commerce business marketing strategies.

\section{Background of E-commerceLivestreaming}

E-commerce livestreaming is a kind of video shopping guide with strong result orientation, which refers to the recommendation of commodities by e-commerce enterprises to consumers by means of online live broadcasting and the promotion of purchase through interaction. It consists of four elements: scene, anchor, content, and interaction. The scene refers to the live design of the live webcast. The anchor refers to the host of the e-commerce livestreaming, which connects the goods with the consumers. Content refers to the information that sellers deliver to consumers in e-commerce livestreaming. Interaction refers to direct information communication between consumers and sellers (anchors) and among consumers in the process of live broadcasting. E-commerce livestreaming has two advantages. First, the transaction cost is low. It provides consumers with more abundant commodity information than graphics and text, and timely answers to consumers' questions on the spot, which reduces the transaction costs of consumers' access to information. Second, it gives consumers a sense of group consumption. E-commerce enterprises gather consumers with common Consumption needs and preference through live webcasting. By displaying the number of participants and speeches on live webcasting pages, the online purchase of individuals is transformed into group shopping.

E-commerce livestreaming is not only a way to visually display commodities to consumers, but also a way for consumers to express their inner resonance and communicate their own needs. Traditional online shopping requires consumers to browse commodity descriptions, customer evaluations, sellers' credits, and then make decisions on purchasing. Multiple monotonous browsing actions and complex judgment programs often increase the difficulty of purchasing decisions. E-commerce livestreaming can reduce the difficulty of consumers' decision-making from three aspects. Firstly, the construction of virtual consumption scenarios for e-commerce livestreaming enhances

ISSN: 0010-8189

(C) CONVERTER 2020

www.converter-magazine.info 
consumers' experience. A virtual shopping site has been created in the e-commerce livestreaming, so that consumers can view more details of the corresponding commodities according to their own preferences and needs, and get trial service by the anchor, which increases the consumer's on-site experience. Secondly, e-commerce livestreaming can make up for the missing information of consumers. During the process of live selling, watching the response of the anchor to other users and the users' speech on the live page allows the consumers to pay attention to other missing information, which helps them make decisions on purchasing. Third, e-commerce livestreaming can enhance persuasiveness to consumers by referring to purchasing decisions of others. The live broadcast page usually displays the prompt "someone has placed an order", giving the audiences a psychological suggestion that the commodity is worth buying, which enhances the persuasiveness of the live display and even leads to the herd effect.

\section{Theoretical Basis and Research Hypotheses}

Driven by information technology, e-commerce livestreaming has become a new way for e-commerce enterprises to promote sales. Based on the "stimulus-organism" theory, consumers are stimulated by the outside world, which will bring them psychological reactions and influence their behavior. Belkclassified external stimuli into situations and commodities, and commodity characteristics are the same in different situations [4]. Lutz and Kakkar believed that the situation is independent of consumers and commodities, and the consumer's response to the environment is generated by situational stimuli [5]. Zhao believed that there are incentives to stimulate purchasing in the network environment, and suggested that the exchange of information and experience among shoppers can prompt them to temporarily lose control and produce immediate purchasing [6]. Huang et al. divided this stimulus into marketing stimuli and environmental stimuli [7], online sellers often promote sales by letting consumers continue to feel marketing stimuli. E-commerce livestreaming provides consumers with additional marketing incentives for online shopping by providing more information and timely interaction than traditional online sales.

Information richness is one of the important factors affecting consumers' purchase intention, since they will collect a lot of information to help them make judgments in the process of making purchase decisions. The research of Ju et al. shows that information richness is an antecedent variable that attracts consumers to shop online, and the greater the amount of information, the higher the willingness of consumers to purchase [8]. A virtual shopping site is constructed through e-commerce livestreaming, where consumers can get more direct perceptual knowledge than graphic data by obtaining detailed information of the goods and the trial as needed. Hu et al. found that information richness directly affects trust, and trust directly affects purchase intention [9]. For consumers, the information obtained through active participation in e-commerce livestreaming is more than that obtained through static browsing, which can increase their trust and reduce perceived risk. Li proved through experiments that virtual experience can make commodities more persuasive, and make consumers have more positive and strong emotions and attitudes towards sellers and commodities [10]. Virtual experience is an important factor in decision-making and has a significant impact on the willingness to buy again.

Meanwhile, the real-time interaction between consumers, anchors and other consumers in the process of online live shopping will also create a sense of immersion. Hassanein's study shows that increasing social presence increases the consumers' perceived usefulness, trust, and shopping pleasure, allowing them to develop a more positive attitude [11]. In the process of live broadcasting, the more fully and actively participants communicate, the more consumers can be attracted to join, so that they can quickly change their role to a shopper. Good communication will encourage consumers to put down their vigilance and compensate consumers for their inability to perceive goods directly through their senses. Chen and Yao found that the stimuli of shopping experience exchanges undermines consumers' self-discipline and self-control ability [12], making it easier to generate buying impulses.

\section{H1: E-commerce livestreaming promotes consumers to buy}

Consumer satisfaction with the goods purchased depends on the comparison of transaction costs and perceived benefits in the process of consumption. According to the purchase decision theory and related research, the

ISSN: 0010-8189

(C) CONVERTER 2020

www.converter-magazine.info 
transaction costs other than purchasing price under mobile e-commerce include search cost, evaluation cost and risk cost. Search cost is the time and effort that consumers spend on searching online for commodity information. Evaluation cost is the cost paid or perceived by consumers when comparing and evaluating the attributes of various commodities. Risk cost is psychological and spiritual burdens arising from various risks when consumers are unable to determine the consequences of purchasing decisions. E-commerce enterprises can reduce the transaction costs of consumers through two ways: cost transfer and information exchange. Firstly, the search cost and evaluation cost of consumers are transferred to e-commerce enterprises through the anchor of live webcast. In the live broadcast room, the communication with the anchor helps consumers to convert the fuzzy search into accurate search, reduce the spent by consumers in searching for commodity information, which also helps them sense the commodity attributes in a more intuitive way. Second, the evaluation of commodity by other consumers in the live broadcast room reduces the uncertainty of the consequences of the purchase decision. Consumers can refer to other consumers' speeches on the commodity in the live broadcast room to reduce the cognitive blindness caused by individual thinking.

Consumers have realized the advantages of online shopping with its popularity, such as convenience, abundant information, diversified choices, competitive pricing. However, in the process of online consumption, these advantages do not necessarily translate into the perceived benefits of consumers after shopping. In the e-commerce livestreaming, the live broadcasting room is used as the medium of information transmission. Some after-sales problems, especially the color difference and use effect which are often questioned by consumers, are eliminated before purchasing. It reduces the perception difference between the commodity displayed on the commercial platform and actually received, and get better shopping experience. At the same time, live selling can provide online services similar to the real scene, which satisfies consumers' novelty and improve their perceived interests.

\section{H2: E-commerce livestreaming increases consumer satisfaction}

In the online shopping scene, the commodity information obtained by the consumer is mainly derived from the commodity display of the e-commerce platform, and the e-commerce enterprise has market demand and commodity quality information. While the professional information of the commodity owned by the e-commerce enterprise may not be known or verified by the consumer whether before or after the purchase. The information superiority status of e-commerce enterprises and the opportunistic behavior they may take will make consumers distrust. Then, consumers may choose to get more information from other sources. The low-cost sources of information include the opinions expressed by the opinion leaders of such commodities on the Internet and the commodity experience information provided by web celebrities. Consumers feel more trustworthy whether the information from third parties is positive or negative.

As an external positive stimulus, third-party recommendation changes consumers' psychological perception, which can increase the persuasive power of commodity information displayed by e-commerce enterprises, and reduce the distrust caused by information asymmetry. According to Chang et al. (2012), the decisions of $82 \%$ of consumers who have received positive information from third parties are affected [13]. Hofland's persuasion model believes that information sources are the most important factor affecting the credibility of information. The authority of information sources can greatly increase the credibility of information. The studies of Akdeniz et al. also showed that the higher the independence of third-party information, the higher the consumer's acceptance and trust in the information [14].

It will increase consumer trust in products and bring consumption when e-commerce enterprises actively provide third-party recommendation information in e-commerce livestreaming. These commodities could even become web celebrity products. In a pre-survey of 50 online consumers, it was also found that respondents tended to buy commodities recommended by third parties. The third-party recommendation information had a great driving force for purchase, especially when it was consistent with consumers' original cognition of the commodity. At the same time, third-party recommendation information that is authoritative or can trigger strong emotional reactions of consumers will also affect consumers' perception of commodities. When consumers enter the stage of commodity

ISSN: 0010-8189

(C) CONVERTER 2020

www.converter-magazine.info 
use, their experience tends to be consistent with the third-party information, enlarging the positive experience and increasing their satisfaction with the purchase.

H3: Third-party recommendation plays a moderating role in the relationship between e-commerce livestreaming and sale performance.

\section{Research Design}

\subsection{Data}

Main data in research comes from Tmall owned by Alibaba, China's largest e-commerce company. Tmall is China's leading B2C e-commerce website, with more than 400 million buyers, more than 210,000 sellers, more than 70,000 brands, and has a greater influence in similar websites.In order to study the impact of e-commerce livestreaming on the sales performance of e-commerce enterprises, the research took the lipsticks as samples that were sold by e-commerce livestreaming from 10 a.m. to 22 p.m. every day from September 21, 2016 to October 20 , 2017 in official brand store on Tmall. The lipsticks that were not sold by e-commerce livestreaming during the same period as a paired sample. The paired sample is selected based on the characteristics, such as price, grams, ranking, etc. The following samples were also eliminated to ensure the validity of the study: (1) samples that did not enter the top 300 of the comprehensive ranking and lasted less than 7 days; (2) samples sold for less than 30 days during the sample period; (3) Samples with less than 10 user ratings. Then, we got 164 pairs of samples.

There are two main reasons for choosing lipstick as a sample: First, many studies have shown that women are more susceptible to external information than men [15]. Second, lipstick is an anti-seasonal experience commodity. There are differences in consumers' decision-making between search commodities and experiential commodities. Consumers are more likely to make decisions based on their own knowledge when purchasing search commodities, while tend to follow other people's purchasing decisions or refer to other people's opinions when purchasing experiential commodities [16]. Therefore, users are more likely to be influenced by sales methods and third-party information when buying experiential commodities. Choosing lipstick as a sample is helpful to the development of research.

\subsection{Variable definition}

\subsubsection{Dependent variable}

In this paper, sales performance is measured in terms of sales volume (Sales) and customer satisfaction (CS). The former refers to the sales volume on the day of e-commerce livestreaming. If multiple e-commerce livestreaming occurred during the sample period, the average sales volume is used to measure. The sales volume of the paired sample refers to the sales volume obtained by the same measurement method during the same time period. Customer satisfaction is measured by consumers' online evaluations of both products and services. The evaluation of products is measured by three factors: quality, appearance and sense of use. The evaluation of service is measured by two elements: commodity description and service attitude. The online review of consumer is divided into 5 levels (from -2 to +2 ) using the Likert 5-level scale, -2 indicates that consumers are very dissatisfied with the performance of e-commerce enterprises in this category, while +2 indicates that consumers are very satisfied. For example, if a consumer comment is "poor service attitude", the service attitude is rated as -2 points; if the comment is: "no color difference at all", the commodity description is rated as +2 points. Since the consumer's comments are not include all categories, the category not mentioned are rated as 0.0 is just in the middle of the 5-level scale, which can be considered to reflect the neutral feeling of the consumer. Finally, we summarized the satisfaction scores of all elements in the consumer's comment and got a comprehensive satisfaction score of 5 levels.

\subsubsection{Independent variable}

The main explanatory variables in this paper are e-commerce livestreaming (Live) and third-party recommendation (TP). Live is a virtual variable, the value is 1 when the commodity is sold by e-commerce livestreaming, otherwise

ISSN: 0010-8189

(C) CONVERTER 2020 
it is 0 . TP is a virtual variable, the value is 1 if there are third-party recommendations, otherwise it is 0 . These variables are also introduced that usually need to be controlled in e-commerce sales research, such as the nature of commodity brand, the number of similar commodities, the number of brand fans, sales price and so on.

The all definitions of the variables are shown in Table 1.

Table1. Definitions of the variables

\begin{tabular}{c|l}
\hline variable & \multicolumn{1}{c}{ definition } \\
\hline Sales & $\begin{array}{l}\text { sales volume, take the natural log of the sales volume on the day of e-commerce livestreaming. If } \\
\text { multiple live selling occurred during the sample period, take the natural log of the average sales } \\
\text { volume. }\end{array}$ \\
\hline Live & customer satisfaction, is the score of customer satisfaction using the Likert 5-level scale \\
\hline VP & $\begin{array}{l}\text { Virtual variable of whether to use live selling, the value is 1 when the commodity is sold by } \\
\text { e-commerce livestreaming, otherwise it is 0. }\end{array}$ \\
\hline Dome & $\begin{array}{l}\text { Virtual variable of whether there are third-party recommendations, the value is 1 if there are } \\
\text { otherwise it is 0. }\end{array}$ \\
\hline Nsp & Number of similar products sold by e-commerce enterprises during the sample period \\
\hline Power & Price of the commodity purchased by the consumer \\
\hline Com & Number of online comments, take the natural log of the number of online comments. \\
\hline Fans & $\begin{array}{l}\text { Number of consumers collecting the brand, take the natural log of the number of consumers } \\
\text { collecting the brand }\end{array}$ \\
\hline Age & Number of years the brand store has been in Tmall \\
\hline
\end{tabular}

\subsection{Research model}

In order to better control the endogenous influence, DID (Differences-in-Difference) is used in this paper to compare the difference of sales performance between "research samples" (live selling commodities) and "paired samples" (non-live selling commodities). In this paper, the commodities sold by e-commerce livestreaming are used as the processing group, and other non-live selling commodities as the control group, so the samples are divided into 4 sub-samples, that is, the processing group before the e-commerce livestreaming, the processing group after the e-commerce livestreaming, the control group before the e-commerce livestreaming, and the control group after the e-commerce livestreaming. The model (1) is constructed to test hypothesis 1 and hypothesis 2 , and model (2) to test hypothesis 3.

$$
\begin{gathered}
\text { Sales }(C S)=\delta_{0}+\delta_{1} \text { Live }+\delta_{2} \text { Dome }+\delta_{3} N s p+\delta_{4} \text { Com }+\delta_{5} \text { Fans }+\delta_{6} \text { Age }+\varepsilon \\
\qquad \begin{array}{c}
\text { Sales }(C S)= \\
\lambda_{0}+\lambda_{1} \text { Live }+\lambda_{2} T P+\lambda_{3} \text { Live } \times T P+\lambda_{4} \text { Dome }+\lambda_{5} N s p+\lambda_{6} \text { Com } \\
+\lambda_{7} \text { Fans }+\lambda_{8} \text { Age }+\varepsilon
\end{array}
\end{gathered}
$$

\section{Empirical Analysis and Conclusions}

5.1 Descriptive statistics of related variables

At present, there are 288 cosmetic stores on Tmall, whose commodities are sold directly by manufacturers. 124 of them sell 2,262 kinds of lipsticks.It is found that the proportion and the frequency of domestic brands using e-commerce livestreaming $(64.9 \%)$ are higher than those of international brands. The proportion of commodities using carefully arranged special venues for live broadcasting is low, only $42.85 \%$. The person hosting the

ISSN: 0010-8189

(C) CONVERTER 2020 
e-commerce livestreaming included customer service staff,network celebrities and cosmetics editors, among which customer service staff accounts for the highest proportion (78.57\%). The peak number of consumers entering the live broadcasting room appears between 20:30 and 21:30, but there is no significant difference in the number of consumers in the rest of the time. It may be related to the use of mobile phone APP in Taobao live broadcasting. The descriptive statistics of related variables are shown in Table 2.

Table2. Descriptive statistics

\begin{tabular}{cccccccccc}
\hline $\begin{array}{c}\text { Variabl } \\
\mathrm{e}\end{array}$ & Sales & CS & Live & TP & Dome & Nsp & Power & Fans & Age \\
\hline mean & 6.879 & 0.928 & 0.500 & 0.373 & 0.614 & 5.826 & $\begin{array}{c}135.75 \\
0\end{array}$ & $\begin{array}{c}14.19 \\
6\end{array}$ & 6.116 \\
Max & 9.289 & 2.000 & 1.000 & 1.000 & 1.000 & $\begin{array}{c}20.00 \\
0\end{array}$ & $\begin{array}{c}320.00 \\
0\end{array}$ & $\begin{array}{c}15.87 \\
1\end{array}$ & $\begin{array}{c}11.00 \\
0\end{array}$ \\
Min & 4.310 & $\begin{array}{c}-2.00 \\
0\end{array}$ & 0.000 & 0.000 & 0.000 & 1.000 & 79.000 & $\begin{array}{c}12.32 \\
9\end{array}$ & 3.000 \\
median & 7.151 & 0.915 & 0.500 & 0.000 & 1.000 & 6.000 & $\begin{array}{c}158.00 \\
0\end{array}$ & $\begin{array}{c}13.74 \\
2\end{array}$ & 6.000 \\
\hline
\end{tabular}

5.2 The relationship between e-commerce livestreaming and sales performance

Table 3 shows the regression results of testing hypotheses 1 and 2. The full sample test shows that the coefficient of Live is significantly positive when the dependent variable is Sales and the coefficient is not statistically significant when the dependent variable is the CS. It indicating that using e-commerce livestreaming can improve sales efficiency, while the impact of consumer satisfaction is not significant.Furthermore, considering that there may be differences in the consumption behavior of consumers with different consumption powers, we used the purchasing power of consumers to divided the samples into two groups and tested, which is recorded as H-power when the purchase price is higher than the median and L-power when lower than the median. Grouping test results show that in group H-power, Live is significant positively correlated with Sales, while Live's coefficient is positive but not significant when the dependent variable is CS. It indicates that e-commerce livestreaming can affect consumers' purchase decision to some extent. In group L-power the coefficient of Live is 0.015 and reaches a significant level of $5 \%$ when the dependent variable is Sales. And the coefficient of Live is 0.006 , which is significant at the level of $10 \%$ When the dependent variable is CS. In order to verify the difference reliably in the effect of e-commerce livestreaming on consumers with different purchasing power, we used Chow test. It is found that the coefficients of Live in group H-power and group L-power were significantly different from each other $(\mathrm{P}<$ 0.001). The above conclusions indicate that there are significant differences in the impact of e-commerce livestreaming on the sales performance of e-commerce enterprises when considering the purchasing power of consumers. The impact of live selling on consumers with high purchasing power is mainly to increase their willingness to purchase. For consumers with lower purchasing power, it can promote purchasing and increase their satisfaction with the commodities. The possible explanation is that consumers with lower purchasing power are more susceptible to the influence of live scenarios and information exchange in their purchase decisions. The commodity perception provided in the process of the live broadcasting will extend to the use of commodities and improve their satisfaction with commodities. The purchase decision of consumers with higher purchasing power is more affected by the brand. Live selling only helps to convert the intention into behavior of purchase. The effect of e-commerce livestreaming on improving commodity satisfaction is not obvious, and the perception of commodity experience for them is more objective.

Table 3. The relationship between e-commerce livestreaming and sales performance

\begin{tabular}{ccccccc}
\hline \multirow{2}{*}{ Variable } & \multicolumn{2}{c}{ Full Sample } & \multicolumn{2}{c}{ H-power } & \multicolumn{2}{c}{ L-power } \\
\cline { 2 - 7 } & Sales & CS & Sales & CS & Sales & CS \\
\hline \multirow{2}{*}{ Cons } & $0.082^{* * *}$ & $0.046^{* * *}$ & $0.098^{* * *}$ & $0.041^{* * *}$ & $0.076^{* * *}$ & $0.048^{* * * *}$ \\
& $(2.38)$ & $(2.64)$ & $(3.91)$ & $(3.95)$ & $(5.37)$ & $(3.62)$
\end{tabular}

ISSN: 0010-8189

(C) CONVERTER 2020

www.converter-magazine.info 


\begin{tabular}{ccccccc} 
Live & $0.011^{*}$ & 0.002 & $0.009^{*}$ & 0.001 & $0.015^{* *}$ & $0.006^{*}$ \\
& $(1.88)$ & $(1.16)$ & $(1.74)$ & $(0.97)$ & $(2.06)$ & $(1.79)$ \\
Domestic & 0.001 & 0.002 & -0.001 & 0.001 & $0.003^{*}$ & 0.001 \\
& $(0.77)$ & $(1.19)$ & $(-0.46)$ & $(0.92)$ & $(1.70)$ & $(0.58)$ \\
Nsp & -0.001 & $0.011^{* *}$ & -0.003 & 0.005 & $0.007^{*}$ & $0.004^{*}$ \\
& $(-0.83)$ & $(2.06)$ & $(-0.84)$ & $(1.58)$ & $(1.83)$ & $(1.83)$ \\
Com & 0.008 & $0.007^{*}$ & $0.014^{*}$ & 0.003 & $-0.004^{*}$ & $0.009^{*}$ \\
& $(1.57)$ & $(1.93)$ & $(1.89)$ & $(1.25)$ & $(-1.76)$ & $(1.93)$ \\
Fans & $0.013^{* *}$ & $0.006^{*}$ & 0.001 & $0.007^{*}$ & $0.021^{* * *}$ & 0.003 \\
& $(2.01)$ & $(1.71)$ & $(0.48)$ & $(1.66)$ & $(3.19)$ & $(0.87)$ \\
Age & $0.010^{*}$ & 0.004 & $0.017^{* *}$ & -0.002 & 0.001 & -0.002 \\
Adj-R2 & $(1.72)$ & $(0.86)$ & $(2.26)$ & $(-0.68)$ & $(1.12)$ & $(-0.87)$ \\
N & 0.1064 & 0.1099 & 0.1087 & 0.0984 & 0.1153 & 0.1061 \\
\hline
\end{tabular}

\subsection{The moderating effect of third-party recommendation}

Table 4 shows the impact of e-commerce livestreaming on the sales performance of e-commerce enterprises and the interactions with third-party recommendations in the process. In table 4 regression results show that when the dependent variable is the sales volume of the commodity, the coefficient of Live x TP in the whole sample and group L-power is significantly positive, and is significant at the levels of 5\% and $1 \%$ respectively, and the coefficient of the interaction term in group H-power is not statistically significant. The results of Chow test indicate significant differences between the two groups $(\mathrm{P}<0.001)$. It indicating that the third-party recommendation can increase the sales promotion effect of e-commerce livestreaming to consumers with lower purchasing power. The possible explanation is that the external information originating from the third party and the information in the live broadcast correspond to each other, which can enhance the credibility of the information presented in the e-commerce livestreaming. Meanwhile, the third-party recommendation information usually contains some professional information related to the commodity, and provides additional information content compared to the live information. When the dependent variable is CS, the coefficient of Live x TP is significantly positive only in group H-power, but not in the whole sample and group L-power. It indicating that the positive joint effect of third-party recommendation and commodity satisfaction is strong for consumers with high purchasing power. This may be because higher-priced commodities have better utility and are more likely to be consistent with third-party evaluation. Then consumers who buy high-priced commodities more agree with their purchase. Consumers who purchase low-priced commodities may have high expectations because of third-party recommendations. The difference between the consumer experience and expectations has weakened consumer satisfaction.

Table 4. The moderating effect of third-party recommendations

\begin{tabular}{ccccccc}
\hline \multirow{2}{*}{ Variable } & \multicolumn{2}{c}{ Full Sample } & \multicolumn{2}{c}{ H-power } & \multicolumn{2}{c}{ L-power } \\
\cline { 2 - 7 } & Sales & CS & Sales & CS & Sales & CS \\
\hline \multirow{2}{*}{ Cons } & $0.011^{*}$ & $0.032^{* * *}$ & $0.013^{*}$ & $0.037^{* * *}$ & $0.016^{* * *}$ & $0.025^{* * *}$ \\
& $(1.69)$ & $(2.89)$ & $(1.71)$ & $(3.51)$ & $(3.21)$ & $(3.16)$ \\
Live & 0.005 & 0.001 & $0.005^{*}$ & 0.002 & 0.004 & 0.005 \\
& $(1.56)$ & $(1.04)$ & $(1.87)$ & $(0.93)$ & $(1.58)$ & $(1.55)$ \\
TP & $0.013^{*}$ & $0.006^{*}$ & $0.021^{* *}$ & -0.004 & $0.028^{* * *}$ & $0.012^{*}$ \\
& $(1.71)$ & $(1.66)$ & $(2.52)$ & $(-1.46)$ & $(5.27)$ & $(2.05)$ \\
Live*TP & $0.019^{* *}$ & 0.003 & 0.003 & $0.010^{* *}$ & $0.017^{* * *}$ & 0.003 \\
& $(2.17)$ & $(1.55)$ & $(1.52)$ & $(2.34)$ & $(3.54)$ & $(1.06)$
\end{tabular}

ISSN: 0010-8189

(C) CONVERTER 2020 


\begin{tabular}{ccccccc} 
Domestic & 0.003 & -0.001 & 0.002 & -0.003 & 0.002 & -0.002 \\
& $(0.96)$ & $(-1.02)$ & $(1.04)$ & $(-1.17)$ & $(0.45)$ & $(-0.81)$ \\
Nsp & $0.009^{*}$ & -0.000 & 0.004 & -0.001 & $0.005^{*}$ & $0.006^{*}$ \\
& $(1.67)$ & $(-0.44)$ & $(1.36)$ & $(-0.82)$ & $(1.74)$ & $(1.74)$ \\
Com & $0.043^{* *}$ & $0.006^{*}$ & $0.016^{* *}$ & 0.005 & $-0.072^{* *}$ & $0.007^{*}$ \\
& $(2.49)$ & $(1.69)$ & $(2.48)$ & $(1.62)$ & $(-2.06)$ & $(1.85)$ \\
\multirow{2}{*}{ Fans } & $0.008^{*}$ & $0.004^{*}$ & 0.003 & $0.006^{*}$ & $0.012^{* *}$ & 0.003 \\
& $(1.66)$ & $(1.67)$ & $(1.29)$ & $(1.81)$ & $(2.35)$ & $(1.03)$ \\
Age & 0.004 & $0.007^{*}$ & 0.001 & $0.009^{* *}$ & 0.001 & $0.006^{*}$ \\
Adj-R2 & $(1.10)$ & $(1.78)$ & $(0.94)$ & $(2.03)$ & $(0.20)$ & $(1.66)$ \\
N & 0.1018 & 0.0924 & 0.0783 & 0.1017 & 0.1256 & 0.0976 \\
\hline
\end{tabular}

\subsection{Robustness test}

In order to test the reliability of the above conclusions, the following robustness tests are carried out: (1) Repeating the test by re-pairing similar commodities of the same brand with similar prices. The test results are the same as those of the above-mentioned pairing method, and the significance is higher, which may be due to the substitution of similar commodities of the same brand;(2) In order to avoid the systematic bias caused by grouping by median, we divided the sample into three groups by the price of the commodity purchased. The group with the highest price is group H-power, while the group with the lowest price is group L-power. Then validation process is repeated again, and the conclusions are still valid.

\section{Research Conclusions}

In this paper, we use the lipsticks sold live online in China from 2016 to 2017 as a research sample, and use DID to empirically examine the relationship between e-commerce livestreaming and sales performance of commodities by grouping customers according to their purchasing power.

The study found that compared with matching companies, the sales volume of e-commerce enterprises using e-commerce livestreaming has increased significantly. The purchasing behavior of consumers with lower purchasing power is more promoted by live sellingcompared with consumers with higher purchasing power. It is also found in further analysis that third-party recommendations have a positive effect on the improvement of commodity sales performance.The research conclusions show that the third-party recommendation significantly increases purchase of consumers with lower purchasing power, and also increases the satisfaction of consumers with high purchasing power. It is not entirely achieved by the consumer obtaining additional information to reduce the asymmetry of the commodity information, but is obviously related to the high reference point of the commodity experience in the third-party recommendation.

The conclusions of this paper are helpful to understand the economic consequences of e-commerce enterprises using e-commerce livestreaming and the mechanism of the effect of e-commerce livestreaming on commodity sales performance. It also has the following policy implications: (1)consumers' purchasing decisions are influenced by the external incentives provided by e-commerce livestreaming. The perception difference of consumer in e-commerce livestreaming largely determines whether the purchase intention can be converted into purchase behavior. Therefore, enriched degree of information and interactive quality are issues that e-commerce enterprises must pay attention to in network marketing. (2) When consumers are faced with purchasing power constraints, the third-party recommendation information will bring high psychological expectations to consumers with low purchasing power. Increasing the objectivity of commodity display helps to improve consumers' satisfaction with commodities.

\section{Acknowledgments}

ISSN: 0010-8189

(c) CONVERTER 2020 
This research was supported in part by Research Grant from MOE (Ministry of Education in China) Project of Humanities and Social Sciences (Grant number 18YJC880008), Natural Science Foundation and Social Science Foundation of Chongqing Municipality in China (Grant numbers cstc2018jcyjAX0835 and 2018YBJY113), and the Scientific Research Project Foundation of Chongqing University of Education (Grant numbers KY2018TZ01, 19GSKP01 and KY201903A).

\section{References}

[1]S.R.Chandukala, J. P.Dotson,Q. Liu, et al.,"Exploring the Relationship Between Online Search and Offline Sales for Better "Nowcasting"," Customer Needs \& Solutions, vol.1, no. 3, pp. 176-187, 2014.

[2]J.P.Vaccani, H.Javidnia, S.Humphrey-Murto."The effectiveness of webcast compared to live lectures as a teaching tool in medical school," Medical Teacher, vol. 38, no. 1, pp. 59-63, 2016

[3]O.Philip, D.Aidan, A.Pavel.“To M-Pay or not to MPay-Realising the potential of smartphones: Conceptual Modeling and empirical validation,” Electronic Markets Markets, vol. 22, no. 4, pp. 229-241,2012.

[4]R.W. Belk. "Situational Variables and Consumer Behavior, Journal of Consumer Research, no. 2, pp. 157-163,1975.

[5]R.J.Lutz, P. Kakkar.“The psychological situation as a determinant of consumer behavior," Advances in Consumer Research, vol. 2, no. 1, pp. 439-453, 1975.

[6]H.X.Zhao, Z.H. S. Cai, He."The Relationship Between Online Merchandise Displaying,Online Interaction and Impulsive Buying Based on Virtual Tactility,” Chinese Journal of Management, vol. 11, no. 1, pp. 133-141, 2014.

[7]M.X.Huang, L.Lei, H.W.Zhu."Money or Romance: How Should Companies Lead Consummers in We-media Sharing?"no. 2, pp. 211-220,2016.

[8]Y.B.Ju, L.Zhao, B. Wang."From visual community members to C2C e-commerce buyers: trust in visual communities and its effect on consumers' purchase," Electronic Commerce Research and Applications, vol. 9, no. 4, pp. 346-360, 2010.

[9]H.Q.Hu, J.Y.Yan, L.Xu.“Information Richness, Purchasing Cost,” Channel Mode and Consumer Purchasing Behavior, no. 5, pp. 80-88,2012.

[10] H. Li."The Influence Mechanism of Virtual Experiential Marketing on Customer Online Behavior-Take Online Airline Ticket Sales as Example,” China Business and Market, no. 10, pp. 110-116,2015.

[11]K.Hassanein, M.Head."Manipulating perceived social presence through the web interface and its impact on attitude towards online shopping," International Journal of Human - Computer Studies, vol. 65, no. 8, pp. 689-708,2007.

[12]C.C Chen, J.Y.Yao."What drives impulse buying behaviors in a mobile auction? the perspective of the stimulus-organism-response model,” Telematics and Informatics, vol. 35, no. 5, pp. 1249-1262, 2018.

[13]Y.P.Chang, W.F.Xiao, W.Qun et al.,"The influence mechanism of third-party product reviews(tprs) on impulse buying intention within the internet environment:by product category and commentators rank for regulation variables," ActaPsychologicaSinica, vol. 44, no. 9, pp. 1244-1264,2012.

[14]B.Akdeniz, R.J.Calantone, C.M.Voorhees."Effectiveness of marketing cues on consumer perceptions of quality: the moderating roles of brand reputation and third-party information," Psychology and Marketing, vol. 30, no. 1, pp. 76-89,2013.

[15]K.Mori, M.Arai "No need to fake it: Reproduction of the Asch experiment without confederates," International Journal of Psychology, vol. 45, no. 5pp. 390-397, 2010.

[16]B. Xiao,I.Benbasat."Product-related Deception in E-Commerce: A Theoretical Perspective,” MIS Quarterly, vol. 35, no. 1, pp. 169-195,2011

ISSN: 0010-8189

(C) CONVERTER 2020 